\title{
0 sentimento de insegurança na discursividade sobre o crime
}

JOSÉ MANUEL PIRES LEAL*

\section{Resumo}

O artigo que se apresenta tem com objecto de análise a representação do sentimento de insegurança face ao crime, com base no estudo comparativo de duas comunidades em Portugal, cujos modelos dominantes de sociabilidade pouco se assemelham - concelho de Mértola e linha de Sintra; concelho de Mértola erodido por uma contínua desertificação demográfica, e linha de Sintra em crescente expansão urbanística e demográfica.

Procurou-se interpretar os discursos produzidos pelos entrevistados, sujeitos à influência não só dos signos e mecanismos que definem a modernidade, como ao efeito socializante dos grandes paradigmas que marcam a vivência nas sociedades contemporâneas. Normatividade e ruptura face ao estabelecido são uma constante ao longo do artigo.

Não existe um sentimento de insegurança. O que habita os indivíduos são uma pluralidade de formas de expressar os receios construídos a partir do cruzamento de variáveis como: o tipo de solidariedade dominante na comunidade ou no local de residência; a proximidade residencial de locais vincados pela exclusão e por assimetrias socioculturais e económicas; e a experiência de vitimação directa ou emocionalmente próxima. Conclui-se que tais variáveis condicionam as práticas e as representações que os indivíduos vão construindo acerca da definição dos agentes e suas motivações para o comportamento desviante, assim como da eficácia dos mecanismos de controlo social.

Palavras-chave: Crime. Delinquência. Sentimento de insegurança. Urbano. Rural.

* Licenciado em Sociologia e Planejamento, mestre em Criminologia. Doutorando em Criminologia pela Faculdade de Direito da Universidade de Porto. 


\section{Introdução}

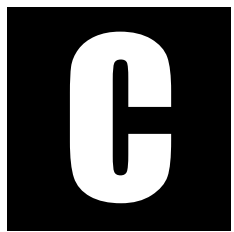

ompreender o sentimento de insegurança na sociedade portuguesa das últimas décadas do século $\mathrm{XX}$, implica perceber as alterações económicas, políticas, sociais e culturais que atravessaram a história portuguesa, especialmente a partir da revolução dos cravos de 1974. A democratização do sistema político e a liberalização da economia desenvolveram o modelo capitalista, com implicações ao nível das relações sociais e dos estilos de vida. Efectivamente a adesão de Portugal, em 1985, à então denominada Comunidade Económica Europeia (União Europeia), proporcionou o impulso inicial para que a sociedade portuguesa rompesse o estado isolacionista e obscurantista a que o regime ditatorial a tinha votado, impelindo-a no alcance de uma modernidade que, conforme referem José Viegas e Firmino da Costa (1998), embora reflexiva ainda se encontra num estado inacabado.

Assiste-se ao contínuo deslocamento demográfico das zonas rurais para as zonas urbanas, não só em busca de um quotidiano menos ligado à terra e regulado pelo ciclo natural das estações, mas também porque a expansão do sector secundário e terciário passaram a exigir mais mão-deobra. Ocorre, assim, um processo denominado de litoralização demográfica, definido pelo movimento unidireccional dos vários fluxos de migração interna, perdendo as regiões interiores do país população para a faixa litoral do território nacional, em particular para as zonas urbanas. Do meio rural, saía-se em simultâneo ora para o estrangeiro, ora para as zonas urbanas.

Portugal atravessa uma situação paradoxal por relação aos seus parceiros europeus. Embora apresente características condicentes com as tendências europeias ${ }^{1}$ é também portador de características que susci-

1 Baixas taxas de natalidade e fecundidade; elevadas taxas de envelhecimento da população; maior peso das classes médias urbanas; aumento do valor da taxa de actividade feminina; progressivo envelhecimento da população; aumento da esperança média de vida; etc. 
tam algum défice de modernização, revelador do seu estado inacabado². Porque, embora a tendência dos índices de desenvolvimento continue a crescer, subsistem ainda situações paradoxais não só ao nível do sector produtivo como ao nível humano, que fazem com que o índice médio de desenvolvimento e bem-estar do país e dos seus cidadãos fique aquém da média dos países considerados no centro ou o centro do desenvolvimento europeu (VIEGAS; COSTA, 1998).

A evolução da sociedade portuguesa, e das suas estruturas produtiva, social, e cultural, que no fundo a fundamentam e lhe conferem sentido, desenvolveu-se nas últimas décadas de forma a originar um plano territorial assimétrico. Se externamente não alcança a média de desenvolvimento da União Europeia (UE), no plano interno, o processo de desenvolvimento e investimento económico gerador de trabalho e emprego produz duas realidades distintas, a concentração de indivíduos nos grandes centros urbanos do litoral, e o êxodo de indivíduos a partir do interior, em particular dos meios rurais, ou ruralizados.

Não obstante o deficit de desenvolvimento da sociedade portuguesa face à maioria dos parceiros europeus, Portugal apresenta tendências demográficas e urbanísticas similares aos outros países da UE, e como tal manifesta problemas relativos à segurança dos seus cidadãos semelhantes aos seus parceiros. Sociedades que assentam sobre o mesmo modelo sócio-politico de desenvolvimento, revelam tendencialmente, em graus diferenciados, fenómenos de carácter desviante análogos, entre os quais a manifestação do crime.

2 Baixo nível de qualificações escolares e profissionais da população portuguesa; ainda uma significativa taxa de analfabetismo; deficientes dinâmicas de modernização económica desacompanhadas por um mecanismo de requalificação dos recursos humanos indispensáveis para assegurar a sua existência, manutenção e evolução, potenciando a existência de segmentos da população que ficam excluídos, podendo desse modo virem a constituir e a engrossar as novas formas de pobreza social. 
Com o progressivo aumento populacional nas cidades e o consequente êxodo demográfico nos meios rurais, e em particular no interior do país, os meios de comunicação de massas tornaram-se num poderoso veículo de transmissão de mensagens essenciais à coesão dos indivíduos e à estruturação da própria identidade, susceptíveis de produzir modelações validadas tanto no plano urbano como rural.

Daí que seja pertinente questionar, se a vivência nesses espaços distintos - meios urbano e rural - com realidades, ritmos e quotidianos específicos, suscitam ainda no indivíduo a expressão de atitudes, representações e praticas sociais condicentes com as características tradicionais do meio onde desenvolve a sua vida e as suas qualidades pessoais. Ou, se pelo contrário, o processo de globalização, com a larga difusão de carga informativa através dos meios de comunicação de massas, exerce uma influencia tal sobre a percepção do indivíduo, que suscita nesse o entendimento do seu quotidiano, não a partir da experiência vivencial e interacional com o outro e com o meio, mas a partir de outros esquemas imagéticos, produtos da exposição às vagas informativas veiculadas pela opinião pública e pela comunicação social.

No presente artigo procurar-se-á determinar se o tipo e a intensidade do sentimento de insegurança é experienciado e construído pelos indivíduos da mesma forma, independentemente do local onde possam residir - espaço urbano, ou rural. Como definem o crime, enquanto comportamento desviante e associal, os seus autores, e as suas motivações?

Na sequência de alguns estudos, a que se fará referência no decurso do artigo, há que sublinhar que o sentimento de insegurança é construído socialmente, tendo como base simultaneamente o conflito suscitado pela distribuição desigual de recursos, a capacidade distinta dos diversos grupos sociais em se apropriarem deles e os gerirem, e por uma estrutura normativa dominante de referência, a partir da qual se definem cultural- 
mente juízos de valor, e se constroem imagens estereotipadas daquilo que se possa considerar normativizado ou desviado.

\section{Apontamentos sobre o método}

O objecto de estudo centra-se no sentimento de insegurança, construído na óptica dos discursos produzidos por duas populações residentes em 2001 não só em espaços díspares e distantes entre si, como inseridas em ambientes com características de desenvolvimento socio-económico e demográfico distintos: concelho de Mértola - eminentemente rural - e Linha de Sintra - eminentemente urbano.

Tendo em conta a natureza fluida do objecto, optámos por uma metodologia de carácter qualitativo, recorrendo para tal ao instrumento inquérito por entrevista, umas vezes conduzida de forma aberta, outras semi-directiva. O sentimento, enquanto fenómeno emocional, radicado na individualidade de cada actor social tem origem numa estrutura cultural condicionada socialmente. Embora psíquico e profundamente individual, encerra em si um processo socializante. Ao se manifestar nos limites do definido sócio-culturalmente reproduz-se a si mesmo, revalidando as condicionantes da estrutura onde se desenvolve. Procuraremos compreender o modo como os indivíduos constroem os discursos em torno dessas supostas reacções emocionais.

Procedemos à descodificação de expressões antropológicas sobre determinada construção social. Tal objectivo impôs ao processo de recoIha de informação, para além do que era enunciado pelos entrevistados, haveria que registar a dimensão do como é dito. Enquanto entrevistador, o investigador assume e desempenha aí a difícil posição e função de observador participante, interagindo com o entrevistado, registando não só o que esse diz, mas também o que acontece, conferindo aos dados 
continuidade discursiva e sentido, decorrente do contexto em que foram produzidos.

Nesse sentido, procedemos ao processo de selecção das amostras ocorrido em 2001 a partir das duas populações - indivíduos residentes no concelho de Mértola e nos concelhos da Linha de Sintra - tendo ambas sido constituídas no fim do processo por dez unidades de estudo (entrevistas).

Estimulou-se a informalidade na produção dos discursos. As entrevistas tiveram como base um guião constituído por um conjunto de linhas exploratórias que serviram para impulsionar e dinamizar as conversas. Destacamos: rede de vizinhança/laços de solidariedade dominantes no espaço de residência; representações acerca da insegurança no local de residência; percepções dos residentes no concelho de Mértola e na Linha de Sintra, acerca da insegurança existente, respectivamente nas cidades e nas zonas ruralizadas; imagens estereotipadas acerca dos supostos agentes causadores da insegurança; experiências de vitimação; medidas preventivas face à insegurança; o maior receio; a forma de violência representada como potencialmente mais frequente; a insegurança actualmente em comparação com o que parece ter sido o sentimento de insegurança há dez anos; opiniões acerca da implementação no ordenamento jurídico nacional as medidas: pena de morte, prisão perpétua e maior facilitação na obtenção de licença de uso e porte de arma de defesa; os órgãos de comunicação social como elementos importantes no processo de construção do discurso.

No final da recolha das entrevistas e consequente transcrição operou-se uma análise de conteúdo por comparação das tendências discursivas produzidas pelos entrevistados residentes em ambos os espaços, tendo sido tomada como matriz central de análise dos discursos as linhas exploratórias que estiveram na origem do próprio guião.

Em toda a extensão da investigação procurou-se compreender o actor social enquanto intérprete de si, do espaço onde interage, e dos signi- 
ficados sobre o sentimento de insegurança que reproduz criticamente no decurso das interacções que estabelece com os outros.

\section{A questão da insegurança}

Independentemente de qualquer edifício teórico-critico referente aos conceitos de desvio e controlo social, o crime enquanto comportamento desviante é lesivo dos valores e normas fundamentais e estruturantes da sociedade, e como tal, atentatório da ordem social. Na esteira de Émile Durkheim (1993) o fenómeno crime representa parte da expressão sintomática do estado anómico da sociedade, da impossibilidade de se tornar abrangente. A função da norma na sociedade, enquanto elemento integrador e conducente dos indivíduos aos papéis funcionais da comunidade, encontra-se de algum modo diluída na heterogeneidade dos mecanismos que enformam a modernidade e a globalização. Esse apenas aparente desfasamento do social defronte ao individual é resultante do modo e das relações de produção vigentes e dominantes nas sociedades modernas, e dos estilos de vida que a partir daí se diversificaram e desenvolveram.

Na óptica de Michael Hechter (1987) a longevidade de qualquer comunidade está ligada ao tipo de controlo vigente, o qual estimula necessariamente o grau e o sentido de solidariedade existente entre os seus membros. As sociedades não sobrevivem apenas devido às garantias das instituições formais de controlo social. O surgimento de mecanismos de controlo informal no seio da comunidade revelam-se como sendo formas mais próximas de controlo sobre o comportamento dos indivíduos, igualmente eficazes na sua regulação. Efectivamente, a especificidade funcional do indivíduo e os papéis que desempenha na comunidade permitem- 
Ihe não só desenvolver a sua personalidade e a sua identidade como também a exposição face aos outros ${ }^{3}$; permite uma maior visibilidade do seu comportamento, e uma maior sujeição ao controlo ritual na interacção com os seus pares, impelindo-o, no plano ideal, ao cumprimento das suas obrigações.

Indubitavelmente o alargamento das cidades, em tamanho e densidade populacional, assim como as opções urbanísticas, estruturais e organizacionais do espaço e de locação dos diversos grupos sociais, muito contribuíram para o progressivo domínio das relações secundárias na vida social dos indivíduos. As exigências que a multiplicidade de papéis sociais exercem sobre o indivíduo, impulsionada pelas sucessivas revoluções e inovações ocorridas nos sectores da ciência e tecnologia, do trabalho e profissões, reflectidas não só na urgência de ser algo, ocupando um lugar no aparelho produtivo, mas também na obrigatoriedade de se destacar, pressionou a capacidade de adaptabilidade do individuo na sociedade. A profusão dispare e coexistente de grupos sociais caracterizados por culturas diferentes, detentores de condições objectivas e capacidades subjectivas de sobrevivência desiguais, marcaram no espaço, em particular das grandes cidades, territórios humanizados diferenciados pelos recursos mobilizáveis.

Independentemente das características sociais, culturais e económicas especificas a cada grupo social, a ideologia do consumo, como meio de suporte do modelo de produção e de modernidade no mundo globalizado, constituiu-se no denominador comum, homogeneizando objectivos culturais sem se ater ao facto de que as oportunidades reais de os alcançarem são desiguais. Tal desfasamento entre objectivos culturais, normas institucionalizadas e oportunidades reais produziram no comportamento do indivíduo processos de resposta e adaptação. Entre elas o crime. No meio urbano profuso de anonimato, os laços primários e tradi-

3 O processo de socialização é já um produto da acção do controlo social, estruturador da comunidade e regulador do egoísmo racional do indivíduo - elemento potencialmente perturbador da ordem social estabelecida. 
cionais que sustentavam a coesão entre indivíduos dão lugar à indiferença e a uma espécie de solidariedade distante. O quotidiano dos indivíduos é dominado pela superficialidade relacional e pelo sublinhar da importância dos símbolos codificados, materializados em bens que revelam não só o estatuto e o lugar de classe do indivíduo, ou do seu agregado, mas também a sua identidade, ou a imagem com que é ou deseja ser identificado.

O processo de marginalização, gerador de exclusão social, funda-se quase sempre numa estratégia de poder e normatividade; os marginalizados e excluídos são representados como indivíduos inadaptados às regras e aos modelos dominantes, por isso comparados demasiadas vezes a uma espécie de grupos sociais dispensáveis. A precariedade socio-económica é invariavelmente uma das causas fundamentais para a exclusão, que os deserda dos vínculos sociais de referência, assentes no paradigma normativizante. A privação de determinados meios materiais, induzidos como necessários e relevantes pelo contexto sócio-cultural dominante, poderá induzir o indivíduo a um progressivo processo de desregulação moral e de dessocialização por referência ao instituído, suscitando por vezes a opção por alternativas marginais. Marcado pelo estigma do desvio, o indivíduo passa a ser identificado pelos outros como uma potencial ameaça à ordem estabelecida, porque susceptível de expressar comportamentos contrários à ética prevalecente na sociedade.

A tipificação de alguns comportamentos enquanto condutas criminalizáveis elencadas no Código Penal e em alguma legislação avulsa, e as molduras penais que lhes estão subjacentes, revelam a estrutura hierárquica de valores e o quadro moral dominante na sociedade. A protecção da vida, da integridade física, e dos valores patrimoniais assumem a ordem geral e hierarquizada dos valores dominantes nas sociedades ocidentais contemporâneas. Não é raro os dois primeiros grupos de valores e outros estarem associados ao terceiro, ou seja a violação dos dois primeiros 
constitui-se demasiadas vezes como mero meio, premeditado ou circunstancial, para se alcançar a ilegítima posse do valor consubstâncializado no bem patrimonial. Tendo como referência as estatísticas da justiça criminal, na última década do século XX cerca de 60 a 70\% dos crimes registados pelas autoridades oficiais portuguesas reportaram-se a crimes contra o património, com destaque para a denúncia do tipo de crime: furto. Tal facto revela a potencial motivação das condutas produtoras deste tipo de crime; determinados indivíduos optam pelo recurso a meios ilegítimos para poderem alcançar objectivos sócio-culturais estandardizados.

Recorrendo aos estudos desenvolvidos por Eduardo Ferreira (1998), as autoridades policiais portuguesas no período de 1993-95 registaram em média um total de 321.212 crimes, sendo que $67 \%$ desse número corresponderam a crimes cometidos contra o património, 21,5\% a crimes contra as pessoas, $10,6 \%$ a crimes contra a vida em sociedade e $0,9 \%$ a crimes contra o Estado. Ao crime de furto corresponderam cerca de $45 \%$ das ocorrências do total de crimes registados, o que por si só revela a importância que este tipo de crime representa no planeamento das políticas oficiais de controlo do crime. A este cenário há a acrescentar os resultados do Inquérito de Vitimação, realizado em 1994 pelo Gabinete de Estudos e Planeamento do Ministério da Justiça, no qual se conclui que só $28 \%$ das vítimas de crimes é que denunciaram os factos às autoridades. Preocupante, para além da relevância percentual de individuos que foram vítimas de um crime e que não o denunciaram às autoridades competentes (72\%), é a argumentação que invocaram para o não terem feito: $43 \%$ declararam que a polícia não poderia fazer nada, 34\% que não se iria interessar e 32\% expressaram que o incidente não tivera importância, constituindo tais dimensões, fortes indicadores da descrença que o cidadão vai revelando acerca do sistema de justiça e do aparelho policial. 
Os tipos de crimes mais denunciados são aqueles que mais atemorizam o cidadão comum, nomeadamente os crimes contra o património e os crimes contra as pessoas, os quais no período de 1993-95 perfizeram em média $88,5 \%$ do total dos crimes registados pelas entidades oficiais. Frequentemente é a ideia da criminalidade comum associada parcialmente ao consumo e tráfico de droga, ao fenómeno da imigração e a alguns grupos de excluídos que enformam as franjas da sociedade, que constituem no imaginário colectivo as grandes causas da construção do sentimento de insegurança.

Mas será que as causas aparentes do sentimento de insegurança são racionais? Eduardo Ferreira (1998), sublinha a ideia de que o sentimento de insegurança é em si uma construção social e como tal passível de subjectividade interpretativa. Todavia, enquanto manifestação simultaneamente emotiva e social, pode definir-se como facto social, e por isso ser experienciado como algo de real, susceptível de despoletar efeitos concretos sobre os processos sociais. Embora o sentimento de insegurança não possa ser confundido com o estado real de insegurança, produzido pelas condutas efectivas de natureza criminosa, ou com as probabilidades efectivas de se poder vir a ser vitimado, as representações sobre o sentimento de insegurança estão quase sempre associadas a experiências directas de vitimação, ou a avaliações quase sempre objectivas acerca da probabilidade de se ser vitimado.

O sentimento de insegurança não resulta só das experiências de vitimação ou da probabilidade de se poder vir a ser vitimado por um acto delinquente, mas também da dinâmica informativa e mediática transmitida ao vivo e em directo pelos média. Esse sentimento, ou a propensão à insegurança na vida moderna, resulta do modo como os poderes públicos e os órgãos de comunicação social gerem tal situação. O lado negro do que é noticia, capaz de prender as audiências, é demasiadas vezes apro- 
veitado por um discurso político legitimador de uma insegurança que no fundo poucos conhecem a amplitude e profundidade. Essas estratégias despoletam na sociedade, e no indivíduo singular, um efeito amplificador da possibilidade do risco e da probabilidade de terem experiências efectivas decorrentes do fenómeno da delinquência. Por isso, sentimento de insegurança e insegurança são realidades na maioria das vezes descoincidentes. O sentimento de insegurança resulta frequentemente de uma forma sobrestimada do fenómeno do crime; propaga-se facilmente por entre os indivíduos, fazendo apelo a uma das mais básicas necessidades do homem: segurança. Nas sociedades modernas, com a profusão de meios de comunicação, e de transmissão de informação, facilmente esse sentimento é alimentado por uma imagem subjectivada e enviesada da delinquência.

Recorrendo aos trabalhos de Sebastian Roché (1993), o indivíduo calcula o risco objectivo de vitimação através da conjugação de diversos mecanismos sociais, como são a comunicação, a confiança na informação veiculada, e a manutenção do controlo social exercido por determinadas instituições. O receio não se difunde apenas a partir da experiência singular. É objecto de uma construção social a qual emerge na sociedade contemporânea, dominada pela estranheza, indiferença e substancialmente pelas relações de carácter secundário.

Sebastian Roché, na esteira de Balkin, sublinha que geralmente as populações mais vitimadas são aquelas que desenvolvem menores sentimentos de insegurança, porque compreendem melhor o risco real de se ser vitimado. Nesse sentido, à medida que a exposição ao crime diminui, o receio de se ser vitimado poderá aumentar. Tudo dependeria do grau de exposição, da probabilidade de se ser vitimado. Atendendo à elevada percentagem de casos nunca reportados às autoridades oficiais, os registos oficiais acerca da criminalidade apenas espelham parcialmente o risco objectivo, e o grau de exposição, do indivíduo face aos comportamentos 
delinquentes, subsistindo uma potencial contradição entre a probabilidade de se poder vir a ser vitimado e as taxas oficiais de vitimação.

Dos dados constantes nos estudos de Eduardo Ferreira, constata-se que as maiores incidências da criminalidade registada no espaço nacional centram-se, de um modo geral, nos distritos situados geograficamente na área litoral do território continental. De que forma se expressa e se diferencia o sentimento de insegurança na litoralidade urbana e na interioridade rural portuguesa? Como é que os residentes no concelho de Mértola, enquanto interioridade ruralizada, e os residentes nos concelhos da Linha de Sintra, enquanto litoralidade urbana, representam os seus receios face ao temor do crime?

\section{Os espaços de Mértola e Linha de Sintra}

O concelho de Mértola integra-se no distrito de Beja, na região do Baixo Alentejo, geograficamente dos mais extensos do país e muito provavelmente dos mais isolados, o que contrasta com o seu volume demográfico, distingue-se como sendo um dos distritos mais deprimidos do país. Para tal têm contribuído a falta de investimento e de desenvolvimento no concelho, motivadores para o despoletar de um processo de êxodo dos seus naturais na senda da emigração ou da migração para as cidades mais desenvolvidas do país como é o caso de Lisboa. Em Mértola os sectores de produção primário e secundário há muito que entraram em declínio. O sector primário, em 1991, ocupava cerca de 29,5\% da população activa em pequenas explorações ligadas à agricultura pecuária, silvicultura, e um reduzido número ligado à pesca artesanal. É frequente as pessoas exercerem várias actividades e não se centrarem só e apenas numa, por não conseguirem dessa os proveitos suficientes para assegurarem a sobrevivência do agregado familiar. Com a redução de importância da indústria 
transformadora e extractiva, é a construção civil que mantém actualmente os 25,3\%da população activa no sector secundário. O sector terciário ligado aos serviços, ao turismo cultural e ambiental, ao pequeno comércio, à presença e intervenção de instituições públicas - finanças, tribunal, e o trabalho proporcionado pela aplicação de projectos municipais - empregam $45,2 \%$ dos activos, os quais representam a vitalidade impulsionadora do fraco desenvolvimento do concelho. Existe neste concelho uma zona que goza do estatuto de Parque Natural do Vale do Guadiana, rio que atravessa o concelho, de modo a salvaguardar as características físicas e naturais do território, assim como o património histórico e tradicional das populações, na perspectiva da promoção do desenvolvimento social e económico das comunidades existentes no concelho.

A área geográfica da Grande Lisboa tem vindo a ser palco de um progressivo crescimento demográfico, tendo nas décadas de 60 e de 70 iniciado uma acentuada tendência ascendente populacional. De 1960 a 1981 verificou-se uma variação demográfica positiva na ordem dos 66,1\%, com especial referência para os concelhos da Amadora e do Seixal. Em simultâneo o concelho de Lisboa inicia uma perda continuada da população residente, com ligeiros e breves períodos de recuperação. Significa que a periferia de Lisboa, em particular os concelhos que apresentam melhores acessos de comunicação ao centro urbano, cresceram em termos demográficos, e consequentemente aumentaram a sua expansão urbanística. Tal não representou propriamente um aumento da área total da Área Metropolitana da Grande Lisboa, mas sim a conquista de espaços outrora rurais, num processo progressivo de aglomeração urbana, principalmente ao longo dos eixos viários e nos concelhos com melhores acessos ao concelho de Lisboa. O concelho da Amadora no período de 1960/70 no compito dos concelhos inclusos na Grande Lisboa, acolheu o maior aumento populacional - uma variação de $137 \%$. Esse aumento populacional no concelho 
da Amadora contribuiu para o congestionamento das suas aglomerações e estruturas urbanas, com os consequentes custos sociais.

Do descrito, não é difícil depreender que as estruturas urbanísticas e as redes de sociabilidade dominantes em ambos os espaços - concelho de Mértola e Linha de Sintra - são profundamente diferentes. Em Mértola, da década de 70 até 1991, a densidade populacional decresceu rapidamente para $7,6 \mathrm{hab} / \mathrm{Km}^{2}$, havendo um profundo desequilíbrio entre a taxa de natalidade - 9,5\% - e a taxa de mortalidade - $15,2 \%$ - provocando uma taxa de crescimento natural negativa, $-5,7 \%$. A ausência manifesta de empregos está patente na baixa taxa de actividade - $25,4 \%$ - e na elevada percentagem - 43,5\% - de população analfabeta em 1981. Em 1991 a população residente no concelho era constituída por 9.805 pessoas, quando em 1960 teve cerca de 27.000 habitantes. Números que por si só constituem prova da corrente contínua de emigração da população existente. Recorrendo aos dados recentes do estudo dos Censos - 2001 - constata-se a tendência em Mértola para a progressiva desertificação demográfica. No período de 1991 a 2001 verifica-se uma variação populacional negativa na ordem dos $-11,1 \%$ de residentes. Estes factos têm repercussões profundas no modus vivendi dos indivíduos, no modo como se encontram estruturados enquanto actores sociais, e no modo como organizam o quotidiano e as redes de sociabilidade que lhes estão subjacentes.

A Linha de Sintra é uma das principais áreas residenciais da Grande Lisboa. Recorrendo aos resultados do último Censos - 2001 - só os concelhos da Amadora e de Sintra locam nos seus territórios 28,7\% (538.344 habitantes) do total da população residente na Grande Lisboa (1.878.006 habitantes). Comparando os dados dos Censos de 1991 e 2001 constata-se que a população residente na Grande Lisboa, nesse período, sofreu uma variação positiva na ordem dos $2,3 \%$. Ainda no mesmo período de tempo considerado o concelho da Amadora perdeu 3,8\% da população residente 
e o concelho de Sintra ganhou cerca de 39,3\% o que é indicador de alguma mobilidade ocorrida em e entre ambos os espaços. Os concelhos da Amadora e de Sintra, no ano de 2001 apresentavam uma densidade populacional respectivamente $7.353 \mathrm{hab} / \mathrm{Km}^{2}$ e $1.094 \mathrm{hab} / \mathrm{Km}^{2}$.

A linha ferroviária Sintra/Lisboa e o eixo rodoviário IC19 foram sem duvida os grandes eixos para a expansão do processo de periferização da Linha de Sintra. Aos fluxos populacionais exógenos, há acrescentar o movimento e o deslocamento de população endógena no sentido Amadora/ Sintra, contribuindo assim para o alargamento da coroa do parque habitacional em torno da capital. As pessoas procuram uma habitação nova e mais acessível em termos económicos. Melhores condições de vida e acesso aos seus locais de trabalho. As comunidades residentes ao longo da Linha de Sintra erigiram-se na dependência com Lisboa e no complexo processo de terciarização. A Linha de Sintra granjeou ao longo das últimas décadas o estatuto de um dos mais importantes dormitórios da capital, de onde todos os dias os residentes partem, em movimentos pendulares, para as suas actividades em Lisboa.

Na vila de Mértola, a via mais movimentada é a que de algum modo atravessa a povoação; todas as outras de certa forma são francamente secundárias, circulando nelas basicamente os residentes, ou algum turista acidental. Os edifícios raramente vão além do primeiro ou do segundo andar, e as pessoas que se cruzam nas ruas, ou se conhecem ou são amigas. $\mathrm{O}$ dito da salvação do dia - bom dia/tarde/noite - inexistente nos meios urbanos de elevada densidade populacional, constitui parte do ritual da boa educação e de reconhecimento entre os residentes em Mértola. Aí toda a gente se conhece, ou no mínimo sabe-se quem é o outro por esse se encontrar referenciado a determinada família. Exceptuando-se os dias de festa na sede do concelho, as noites em Mértola são silenciosas, calmas e tranquilas. Na vila, só ao fim de semana a energia da juventude se faz ouvir pelas ruas. 
A Linha de Sintra encerra em si uma diversidade populacional muito grande. O alargamento urbanístico na Linha de Sintra não se caracterizou apenas pela eclosão de novos aglomerados habitacionais indiferenciados; surgiram nesses espaços periféricos, dos concelhos da Amadora e Sintra, bolsas habitacionais privilegiadas e bolsas de exclusão, produtoras de representações imagéticas de qualidade de vida, mas também de estigma. Tais realidades estão perfeitamente presentes nos discursos produzidos pelas unidades de estudo que de seguida exploramos.

\section{Expressões acerca da insegurança}

Embora exista uma clara dicotomia entre os discursos produzidos pelos residentes no concelho de Mértola e os residentes na Linha de Sintra, conforme se demonstrará, a clara homogeneidade dos discursos dos entrevistados residentes no concelho de Mértola, contrasta com a evidente clivagem existente nos discursos produzidos pelos residentes na Linha de Sintra. Tal facto revelou-se logo no início de cada entrevista; enquanto alguns dos entrevistados residentes no concelho de Mértola, quando se Ihes proferiu a palavra insegurança, a associaram de imediato aos perigos da circulação rodoviária para as crianças e idosos em algumas ruas da vila de Mértola, os entrevistados residentes na Linha de Sintra, associaram de imediato o termo insegurança ao fenómeno do crime. Os conceitos comunidade e sociedade desenvolvidos por Ferdinand Tönnies (1979) têm, respectivamente, correspondência com as redes de sociabilidade dominantes em Mértola e na Linha de Sintra. As características urbanísticas, demográficas, e de sociabilidade existentes em Mértola e Linha de Sintra são responsáveis por urbanidades distintas. 


\section{A rede de vizinhança e os laços de solidariedade}

Na Linha de Sintra encontramos dois tipos distintos de representações simbólicas acerca do sentimento de insegurança e dos seus agentes, sendo que as primeiras evidências explicativas se poderão fundar nas características do local onde habitam e em contactos negativos que resultaram em experiências de vitimação directa.

A elevada densidade populacional na Linha de Sintra, concentrada em prédios descaracterizados, suscita o isolamento, a solidão e a estranheza. Pessoas que habitam no mesmo patamar por vezes não se conhecem, evitam-se, ou simples e naturalmente ignoram-se. Parte-se de manhã para o trabalho, onde se desempenha o papel esperado e regressa-se ao fim do dia. As relações de carácter secundário dominam impedindo a consolidação e o alargamento da rede de vizinhança, e o enfortalecimento dos laços de solidariedade. Os vizinhos? Pouco mais partilham senão as indispensáveis responsabilidades do condomínio, e as típicas saudações de quem apenas deseja manter com os outros uma sociabilidade funcional, estritamente superficial;

Os residentes conhecem os vizinhos mas as relações que estabelecem não são intensas, o controlo social informal é fraco, e por isso ineficaz. As pessoas aparentemente não comungam nada em comum, o que Ihes permite que a atenção da comunidade não esteja permanentemente focada sobre as suas pessoas, facultando-lhes em simultâneo uma sensação particular de liberdade e de independência alargada, mas também uma franca vulnerabilidade às consequências de condutas desviantes, sejam elas meras incivilidades ou atitudes criminógenas, de indivíduos que por pertencerem à amálgama dispersiva e diversa na comunidade, não passam de meros rostos sem nome.

Em Mértola as pessoas não só se conhecem, como os seus quotidianos se interpenetram. A solidariedade social na comunidade é forte porque a malha da rede de vizinhança é estreita, feita de partilha de ne- 
cessidades e cumplicidades; qualquer indivíduo estranho à comunidade é perfeitamente identificado e de certo modo objecto de alguma atenção. Não só o estrangeiro é observado pelos elementos da comunidade, como os próprios elementos da comunidade são sujeitos a um controlo social informal exercido pelos seus pares.

"Sabemos quem vive ao nosso lado, conhecemos as pessoas, sabemos o nome delas." (residente no concelho de Mértola - Miguel)

Na Linha de Sintra domina uma espécie de acordo tácito fundado na indiferença, monitorizado pelas diversas instituições encarregadas do controlo social formal. As pessoas num mesmo prédio conhecem-se, todavia entre elas não existe um relacionamento intenso que suscite um espírito coeso de comunidade. As relações de proximidade que as pessoas mantêm são mantidas com indivíduos espacialmente distantes dos seus locais de residência. Em Mértola, na vila ou no monte, todo o relacionamento se esgota no meio; a envolvente pertinente é o meio na sua totalidade. A segurança do indivíduo é garantida através da conversa mantida acerca da vida deste ou daquele, traduzida na coscuvilhice e na censura por referência aos valores fundados no costume e na tradição, assim como no conhecimento, enquanto constrangimento.

\section{Representações sobre a insegurança no local de residência}

Em Mértola não há insegurança porque simplesmente as pessoas não se sentem inseguras. Tal estado de espírito generalizado a todos os que foram entrevistados é traduzido de forma eloquente por uma das entrevistadas. Embora não negando que o espectro da ideia de insegurança exista, não ocupa permanentemente o espírito dos residentes em Mértola.

"É verdade que de vez em quando pensamos nas questões da segurança e da insegurança. Mas é uma ideia que apesar de eventualmente 
presente, não a sentimos, porque não sentimos insegurança." (residente no concelho de Mértola - Marisa)

Como veremos mais adiante, para que o sentimento de insegurança fosse uma constante no espírito de quem reside em Mértola, não bastam as notícias acerca da criminalidade veiculadas pelos órgãos de comunicação social e pela opinião pública, seria necessário que tais eventos funestos acontecessem no quotidiano das pessoas. Poder-se-á afirmar que mais que o crime, os residentes temem o trânsito que circula em algumas das vias públicas do concelho. Tal receio radica-se na liberdade que os filhos de idade infantil gozam em poderem brincar na rua.

O diminuto sentimento de insegurança expresso pelos residentes em Mértola, face a condutas de natureza delinquente, funda-se no fenómeno recente da toxicodependência. As pessoas têm consciência que o fenómeno da dependência de drogas ilícitas suscita nos toxicómanos a satisfação de necessidades sem hora marcada. Apesar de tudo, referem não terem conhecimento de factos relevantes perpetrados em Mértola por toxicodependentes residentes no concelho. Todavia o sobressalto, o receio e a suspeita existem. De um modo geral, as condutas que geram alguma instabilidade, traduzem-se pelas pequenas incivilidades decorrentes geralmente do comportamento efusivo da juventude, incompreendido pelas gerações mais velhas, porque no fundo alteram o estado contínuo de um modus vivendi há muito estabelecido. O suposto agente de alguma intranquilidade no concelho é em regra atribuído ao indivíduo estranho, que surge sem referências conhecidas ou sem qualquer ligação a alguém da terra. Os poucos casos reportados pelos residentes tiveram como interpretes quase sempre actores estrangeiros.

O sentimento de insegurança na Linha de Sintra não é sentido do mesmo modo por todos os entrevistados residentes nesse espaço. A localização da residência é sem dúvida o factor condicionante para a franca 
clivagem de opiniões expressas acerca da insegurança. Dos entrevistados, cerca de metade residem no concelho da Amadora, em bairros contíguos a bolsas habitacionais dominadas pela pobreza e pela exclusão. São indivíduos com experiências directas de vitimação, quase sempre através do roubo, e com conhecimento de casos de vitimação nos quais foram intervenientes pessoas que lhes são próximas. Tais experiências têm uma influência fundamental nas representações que constroem acerca da insegurança, não só no local onde residem como em toda a zona da Grande Lisboa. Os discursos são atravessados por algum pessimismo e alguma raiva, identificando aqueles que consideram serem os presumíveis agentes do estado de insegurança que sentem. Os indivíduos, pertencentes a grupos minoritários, como alguma minoria étnicas, residentes em bolsas de exclusão conotadas com formas de vida social marginais, são de forma indiferenciada identificados como sendo os geradores do fenómeno da delinquência e por consequência responsáveis pela produção do sentimento de insegurança.

Os restantes entrevistados na Linha de Sintra constroem a percepção acerca da insegurança no local de residência, perfeitamente coadunada com a representação simbólica que possuem acerca do local onde vivem, a qual se confunde com as características socio-económicas e culturais dos grupos que habitam esses espaços. Qualquer desses entrevistados não reside em bairros próximos de zonas habitacionais degradadas ou de bolsas de exclusão. Sentem-se seguros em casa e na rua, pelo que não expressam qualquer sentimento de insegurança; todavia têm consciência que em certas zonas da Linha de Sintra a insegurança poderá ser uma preocupação a ter em conta, como é o caso do local de residência dos dois primeiros entrevistados na cidade. 


\section{O espelho reflexo Linha de Sintra - Mértola}

A representação que os residentes em Mértola constroem acerca da insegurança nas cidades, especificamente em Lisboa, é bastante negativa. De referir que todos os entrevistados conhecem a cidade de Lisboa, tendo alguns deles já residido temporariamente na Grande Lisboa. Todos se referem à criminalidade como o principal fenómeno gerador do clima de insegurança existente em Lisboa; quando se deslocam à capital equacionam algum receio de poderem ser vítimas de determinado comportamento criminoso. Por isso alguns afirmaram só ir a Lisboa quando necessário, sendo que quando aí têm que se deslocar, tomam determinadas medidas preventivas minimizadoras de um possível contacto indesejado.

Os entrevistados residentes na Linha de Sintra têm todos alguma ligação com espaços ruralizados. Ora porque nasceram em aldeias, migrando após a maioridade para a Grande Lisboa, ora porque as suas raízes genealógicas se perdem na memória de um qualquer povoado aldeão, todos têm um motivo para revisitarem a ruralidade desses espaços. Na opinião destes entrevistados o estado de segurança existente em tais terras já não é o mesmo de outrora. Todavia a tranquilidade e a segurança ainda são a marca caracterizadora de tais locais; sabem que alguma da insegurança que os habitantes de tais localidades sentem é gerada por gente de fora, as quais aproveitando-se do melhoramento das vias rodoviárias, facilmente acedem a tais terras, nem sempre com as melhores intenções.

\section{Imagens estereotipadas dos supostos agentes causadores da insegurança}

A maioria dos entrevistados, independentemente do espaço de residência, atribui aos comportamentos consumo e tráfico de drogas a qua- 
lidade de o mais importante agente causador não só do sentimento de insegurança como do próprio clima de insegurança nas cidades. A toxicodependência é encarada como a principal causa geradora da pequena criminalidade, ideia de alguma forma corroborada pelas abordagens jornalísticas que vêm a publico, na intersecção dos fenómenos da toxicomania, marginalidade e delinquência; só os residentes em zonas contíguas a bolsas habitacionais degradadas, proliferas de pobreza e de exclusão, maioritariamente habitadas por indivíduos de origem ou ascendência africana e de etnia cigana, é que associam a tais comunidades minoritárias, de forma indiferenciada, a origem e responsabilidade do fenómeno delinquência, gerador de insegurança.

"A droga é sem dúvida a origem do pequeno crime." (residente no concelho de Mértola - Joaquim) "Não os distingo por raça. São sem dúvida as pessoas necessitadas que recorrem a tal pratica, como os toxicodependentes." (residente na Linha de Sintra - Gabriela)

A aparente desregulamentação das instituições família e escola, fruto de alguma anomia do sistema social, são também apontadas como grandes causas da desintegração do indivíduo e do próprio processo educativo, comprometendo estruturas de referencia que se julgavam seguras; os indivíduos cedem facilmente ao apelo materialista, à pressão cultural, sem que para tal reúnam os meios para alcançarem de forma legitima esses objectivos culturais, salvaguardados pelas normas institucionalizadas. Ficam enredados pela descoincidência entre as oportunidades reais e a pressão dos objectivos culturais a que são sujeitos.

\section{Medidas preventivas face à insegurança}

Os residentes no concelho de Mértola não tomam medidas preventivas especiais face à insegurança porque simplesmente não a sen- 
tem. É frequente as portas das residências estarem abertas, com a chave introduzida no canhão, do lado de fora, ou simplesmente no trinco. Os condutores deixam as viaturas automóveis abertas, com a chave na ignição, enquanto estão no café ou noutros espaços. A confiança é elevada porque a rede de vizinhança e os laços de partilha permitem o exercício do controlo social informal de forma eficaz;

$\mathrm{Na}$ Linha de Sintra constata-se uma vincada clivagem nas medidas preventivas adoptadas face à insegurança por referência à zona de residência. Uma vez mais, os residentes na Amadora são aqueles que demonstraram maior atenção e cuidado face a potenciais ameaças; os residentes no concelho de Sintra revelaram não tomar quaisquer medidas especiais para se precaverem face ao crime. Portas fechadas, à chave ou apenas no trinco, correntes na porta, e alguma despreocupação ao circularem na via pública, são estados considerados integradores de um quotidiano normal, normalizado pela confiança que têm nas características dos locais onde habitam.

\section{O maior receio e as formas de violência representadas como mais frequentes}

O maior receio alimentado no espírito, tanto dos residentes em Mértola como na Linha de Sintra, não tem como referencia a perda violenta de bens patrimoniais, mas sim a afectação da esfera integridade física. Os crimes potencialmente produtores de ofensas à integridade física constituem unanimemente o maior receio dos entrevistados, complementados, em particular nos entrevistados do sexo feminino, dos crimes de natureza sexual;

"O que eu mais receio é ser surpreendido por um indivíduo que surja do nada, e que me atinja na minha integridade física." (residente no concelho de Mértola - Mário) "Os crimes que eu mais receio, são aqueles que incluam agressão física." (residente na Linha de Sintra - Carlos) 
"Roubarem coisas, é algo que custa, mas que com o tempo se esquece, agora ser violada é algo que fica para toda a vida. Se for vitimada e nada acontecer à minha integridade física, eu sei que vou esquecer mais facilmente." (residente no concelho de Mértola - Vanda)

O furto e o roubo são os comportamentos criminógenos considerados unanimemente como os mais frequentes. As formas de violência mais comum e mais noticiadas pelos órgãos de comunicação social. O que significa que o objecto dos potenciais delinquentes centra-se na obtenção ilícita de bens patrimoniais, recorrendo para tal aos tipos jurídicos: furto e roubo, facto de alguma coerência com os valores e objectivos materialistas dominantes nas sociedades modernas;

O roubo, penso que é o crime mais comum. Porque tem a haver com a angariação de dinheiro. (...) Por isso acho que a população que mais pratica esse tipo de crime são os toxicodependentes, que precisam de dinheiro para as suas doses diárias, recorrendo por isso ao roubo. (residente no concelho de Mértola - Marisa)

A toxicodependência, é representada como o fenómeno central gerador de comportamentos desviantes lesivos da estrutura valorativa e normativa estabelecida em qualquer comunidade.

Importa salientar que tanto o roubo como especificamente o assalto à mão armada implicam não só a apropriação ilícita de bens patrimoniais, como a eventual produção de violência física e psicológica sobre as vítimas.

\section{A pena de morte, a prisão perpétua, e a facilidade na obtenção da licença de uso e porte de arma de defesa}

Ao se ter solicitado a opinião acerca da possibilidade do poder executivo diligenciar de modo a implementar no ordenamento jurídico nacional, as bases necessárias para a introdução das medidas punitivas pena 
de morte e prisão perpétua, a maioria dos entrevistados, com a excepção de um dos residentes no concelho da Amadora com várias histórias pessoais de vitimação, expressaram uma negação veemente face à implementação da pena de morte, considerando-a uma medida contrária ao inalienável direito à vida e absolutamente desadequada à realização da justiça.

"Em relação à pena de morte sou absolutamente contra, porque ao se matar quem matou, é um contra-senso. Porque no fundo tanto é criminoso o primeiro acto como aquele que é confundido com um acto de justiça. Seria um ciclo vicioso." (residente na Linha de Sintra - Gabriela)

Já no que concerne à prisão perpétua alguns dos entrevistados aceitariam tal medida no máximo para punir crimes hediondos em que a vida, a liberdade e a autodeterminação sexual estivessem em causa; todavia existem opiniões que expressam a desacreditação de tal medida como meio de realização da justiça;

Em relação à prisão perpétua, e na sequência da pena de morte, não creio que venha também a resolver o que quer que seja. Porque para já, embora não se aniquile o agente que causou um determinado crime grave, ao encarcera-lo para toda a vida, não se Ihe dá uma oportunidade, consagrada modernamente, que é a reabilitação. (residente na Linha de Sintra - Carlos)

Embora existam alguns diferendos, no que concerne às medidas pena de morte e prisão perpétua, as opiniões demonstraram alguma unanimidade quando se apresentou a possibilidade das autoridades oficiais poderem facilitar, a qualquer cidadão, a obtenção da licença de uso e porte de arma de defesa. Todos os entrevistados recusaram terminantemente tal possibilidade, fundamentando as suas posições no suposto facto de que o aparente controlo que tal medida poderia suscitar sobre o crime, num determinado momento inopinado, poderia transformar-se em descontrolo. 
Poder-se-ão classificar as opiniões dos entrevistados, no que concerne à introdução no ordenamento jurídico de medidas extremas de prevenção, repressão e punição da criminalidade, como posições moderadas. Não só recusam categoricamente a aplicação da pena de morte, por razões de ordem ética e filosófica, como demonstraram algumas reticências quanto à introdução da medida prisão perpétua. No seguimento desta última admitem o agravamento de algumas molduras penais que sancionam comportamentos criminais considerados muito graves, como são os que atentam contra a vida humana, a liberdade e a autodeterminação sexual. Essa posição moderada é reforçada pela recusa, expressa de forma unânime, da implementação de medidas legislativas que facilitem a obtenção da licença de uso e porte de arma de defesa. Tal posição é reveladora, não só da ideia de senso comum, na qual o português médio é por natureza um povo moderado, como do sinal de que na consciência do cidadão médio ainda subsiste alguma confiança nas instituições incumbidas do exercício legal dos mecanismos de controlo social.

\section{A comunicação social enquanto agente no processo de construção do discurso}

Qual o lugar dos órgãos de comunicação social no processo de construção das representações que nos servem como referencias para a prossecução do quotidiano? A teoria do agendamento de Maxwell McCombs (2001) tem explorado esta problemática. Segundo este autor, os indivíduos nas sociedades modernas contemporâneas, são hoje mais do que nunca, devido ao progresso nos domínios da ciência e das novas tecnologias, sujeitos a elevados índices de informação que de algum modo os condicionam. Na óptica do referido estudioso "os elementos proeminentes da imagem do mundo elaborada pelos média, tornam-se também 
proeminentes na imagem que as pessoas têm do mundo" (2001), nesse sentido, os média não só despertam a atenção dos indivíduos sobre determinados temas, em detrimento de outros, como instruem o indivíduo no método supostamente mais adequado para a leitura dos fenómenos. O sensacionalismo é uma estratégia que procura captar atenções e emoções, que no fundo se traduzem em públicos e audiências. Alguns dos entrevistados têm consciência desse efeito premeditado; que permanece presente até nas conversas entabuladas no quotidiano, condicionando o modo de estar e o livre movimento dos indivíduos.

"Acho que o sentimento de insegurança é sentido e vivido pelas pessoas porque estão sempre a falar nisso." (residente na Linha de Sintra - Gabriela) "Há sempre algum comportamento condicionado por conversas anteriores. Por informações que chegam daqui e dali. Por conversas tidas entre as pessoas, ou por informações obtidas através dos meios de comunicação social." (residente na Linha de Sintra - Carlos)

As condutas e os acontecimentos de natureza criminógena noticiados de forma continuada pelos órgãos de comunicação social, produzem nos indivíduos um efeito potenciador e catalisador da atenção desses, porque sabem que desse modo é possível "explorar a estranha curiosidade que as pessoas têm acerca do lado mórbido da vida, e das experiências humanas" (intervenção do marido da entrevistada Anabela). Exemplos do tipo reportado por um dos entrevistados, deve-se mais à ignorância, ao analfabetismo e até mesmo à iliteracia, que propriamente ao possível efeito hipnótico dos média sobre a razão e o entendimento do indivíduo;

Aqui há dias um jornalista perguntava a uma mulher que estava a ouvir um político a falar 'então gostou de ouvir o senhor doutor?' ela disse 'ai, fala muito bem, falou muito bem' e o jornalista perguntou-lhe 'o que é que ele disse?', respondeu 'ah, meu senhor eu não sei, eu não percebi'. Falou muito bem mas ela não percebeu. (residente no concelho de Mértola - Joaquim) 
Que os órgãos de comunicação social exercem influência sobre o modo como os indivíduos constroem as representações acerca da insegurança e do mundo, e como o experienciam, é inquestionável. Todavia, e recorrendo uma vez mais aos estudos de Maxwell McCombs (2001), embora as pessoas estejam sujeitas aos efeitos condicionantes dos média, essas não são coisas susceptíveis de programação. Os média apenas constituem mais um elemento, entre muitos, que influenciam o processo de aprendizagem do indivíduo No ser humano tal programação traduz-se por algum determinismo genético e por um longo e complexo processo de socialização.

\section{Considerações finais}

As definições dos significados do sentimento de insegurança dependem da intercepção de determinados mecanismos sociais como são a comunicação e a confiança no que é veiculado, o exercício do controlo social, e o discernimento simbólico das experiências tidas no quotidiano. Nesse sentido, a insegurança, por referência à problemática da delinquência e da criminalidade, não é sentida e experiênciada de forma homogénea pelas comunidades residentes na Linha de Sintra e em Mértola.

O tipo de rede de vizinhança e a natureza dos laços de solidariedade são elementos fundamentais para a formação do sistema informal de controlo social, eficaz em meios sociais de pequena dimensão. Quanto mais apertada for a rede de sociabilidade no espaço, tendencialmente os laços de solidariedade existentes entre indivíduos revelam-se mais fortes, aumentando a capacidade integradora da comunidade, e a possibilidade de vigilância e controlo dos comportamentos. O inverso produz a dispersão, a indiferença civil, a estranheza, a fraqueza de laços de solidariedade e a ineficácia da rede de vizinhança no exercício do controlo social informal, e como consequência, gerador do sentimento de insegurança, 
resultante da sensação de desintegração comunitária. Nesses casos, aparentemente, a comunidade não existe.

Em Mértola a proximidade entre indivíduos e a partilha complementar de necessidades vincula-os ao respeito e cumprimento do prescrito pelo costume e pela tradição, mas também pelos valores e normas estabelecidas e enformadoras daquilo que são, enquanto unidade social e constituição identitária.

Na Linha de Sintra, a diversidade sócio-cultural e económica dos indivíduos, a disparidade de origem geográfica, e étnica fomenta a dispersão do indivíduo na multidão anónima. Em sociedade o indivíduo comunga com os outros apenas a suposta obrigatoriedade de respeitar e cumprir o prescrito pelos valores dominantes e pelas normas estabelecidas, definidoras do tipo de sociedade. Os indivíduos, ao aparentemente pouco partilharem, sabem que a referencia do controlo social que os guia e sanciona é a que se manifesta formalmente através das instituições especializadas. Nesse sentido, o sentimento de insegurança desenvolve-se com maior facilidade nos grandes centros urbanos, que propriamente nos meios sociais mais pequenos, como é o caso do concelho de Mértola.

No entanto o sentimento de insegurança não é gerado e diferenciado só e apenas a partir de um conceito fundado na estatística e na densidade demográfica. A experiência pessoal de vitimação e o conhecimento de outras emocionalmente próximas constituem elementos importantes no processo de construção da representação do sentimento de insegurança.

No concelho de Mértola o sentimento de insegurança é praticamente inexistente, porque os crimes são raros e como tal a taxa de vitimação é baixa. Na Linha de Sintra constata-se que os indivíduos que mais vezes foram vitimados, sempre por condutas criminosas contra o património, são os que produzem o discurso mais radicado na intolerância, na raiva, e até na xenofobia. Acresce ainda que esses indivíduos vivem em bairros 
contíguos a bolsas de pobreza e de exclusão, ocupadas maioritariamente por minorias étnicas, atribuindo com frequência aos deserdados do contrato social e habitantes de tais bolsas territoriais, a responsabilidade pelos comportamentos desviantes lesivos da ordem social. Os outros entrevistados da Linha de Sintra, residentes em bairros que se situam fora da área de influência das bolsas de exclusão, sentem-se seguros no bairro onde habitam, não necessitando de tomar medidas especiais de prevenção.

Quadro Sinóptico. elementos explicativos da diferença existente entre os sentimentos de insegurança expressos pelos entrevistados residentes em ambos os espaços considerados

\begin{tabular}{|c|c|}
\hline Linha de Sintra & Concelho de Mértola \\
\hline $\begin{array}{l}\text { População muito numerosa; } \\
\text { Elevada densidade populacional; } \\
\text { Rede de vizinhança de uma fraqueza relativa, } \\
\text { dominada por laços de solidariedade mais } \\
\text { centrados no local de residência que na } \\
\text { comunidade; } \\
\text { Domínio das relações secundárias no quotidiano } \\
\text { dos indivíduos; } \\
\text { Domínio do controlo social formal; } \\
\text { Elevado índice de criminalidade; } \\
\text { Forte mas diferenciado sentimento de } \\
\text { insegurança. }\end{array}$ & $\begin{array}{l}\text { População pouco numerosa; } \\
\text { Baixa densidade populacional; } \\
\text { Rede de vizinhança coesa, dominada por laços } \\
\text { de solidariedade centrados na comunidade; } \\
\text { Domínio das relaçôes primárias no quotidiano } \\
\text { dos indivíduos; } \\
\text { Domínio do controlo social informal; } \\
\text { Baixo índice de criminalidade; } \\
\text { Fraco sentimento de insegurança. }\end{array}$ \\
\hline
\end{tabular}

De modo em geral todos os indivíduos se sujeitam à exposição informativa dos média. Decorrente de tal exposição, as estratégias sensacionalistas suscitam no indivíduo a potenciação de algo que de algum modo já se encontrava latente. Nesse sentido, não é difícil que determinados indivíduos residentes na Linha de Sintra em áreas urbanas problemáticas, em razão da criminalidade, e com experiências pessoais de vitimação, assumam posições extremadas, de alguma forma potenciadas pela carga noticiosa negativista e caótica da realidade social. O inverso também é um facto. Em Mértola, as pessoas estão sujeitas às mesmas pressões e influências produzidas pelos média, todavia não sentem insegurança. $\mathrm{O}$ 
problema em Mértola centra-se acima de tudo nas pequenas incivilidades que geram desassossego e algum desconforto, suscitadas principalmente pelo choque entre gerações. Estilos de vida e modos de viver, descoincidentes mas socialmente compatíveis.

Apesar da preocupação acerca do fenómeno criminalidade, e do receio de se poder vir a ser vitimado por uma conduta delinquente, a maioria dos indivíduos conservam uma sólida moderação no que concerne à manutenção, na sociedade portuguesa, dos valores de solidariedade, tolerância e respeito pela dignidade humana, suportada pela confiança que ainda mantêm nas instituições e nos mecanismos de controlo social.

Não obstante o descrito, entre Mértola e a Linha de Sintra, e mesmo no interior desta última, existe uma inegável assimetria não só no que concerne à estrutura urbanística que caracteriza os espaços, como na urbanidade existente entre indivíduos. O tipo de rede de vizinhança dominante define o grau de sociabilidade e de solidariedade entre indivíduos, e por isso a capacidade diferenciada de integração das comunidades. Nada surge do vazio. A acontecer dependerá sempre da prévia existência de condições que suscitem e condicionem a construção social e a representação emocional do sentimento de insegurança.

\section{The feeling of insecurity in the discourse on crime}

\section{Abstract}

This article analyzes the representation of the feeling of insecurity in the face of crime, based on the comparative study of two communities in Portugal, with different models of sociability - concelho de Mértola and linha de Sintra; concelho de Mértola, eroded by a continuous demographic desertification, and linha de Sintra in increasing urban and demographic expansion.

The paper interprets the interviews as a result of the influence of the signs and mechanisms that define modernity, and the socializing effect of the great pa- 
radigms that characterize life in contemporary societies. Normativity and rupture in face of the status quo appear constantly throughout the article.

There is no feeling of insecurity. The individuals have many ways to express the apprehension that results from the intersection of variables such as: the dominant type of solidarity in the community or place of residence; residential proximity to places marked by exclusion and socio-cultural and economic asymmetries; and the experience of victimization, either direct or emotionally close. It appears that these variables influence the practices and representations that individuals create to define the agents and their motivation for deviant behavior, as well as the efficacy of the mechanisms of social control.

Keywords: Crime. Delinquency. Feeling of insecurity. Urban. Rural.

\section{Referências}

Associação de Desenvolvimento Integrado. Caracterização e Diagnóstico Social do Concelho de Mértola. Rota do Guadiana - Projecto Ombro a Ombro, (s/d).

Atelier de Sociologia Urbana, Sociologia populacional da área metropolitana de Lisboa - uma aproximação aos dados estatísticos, 1960-1970-1981, Sociologia Problemas e Práticas, n. 01, 1986.

DURKHEIM, Émile. A Divisão do Trabalho Social. 1 v. e 2 v. Lisboa: Editorial Presença, (s/d).

. As regras do método sociológico. 5 ed. Lisboa: Editorial Presença, 1993.

. O Suicídio. 5 ed. Lisboa: Editorial Presença, 1992.

FERREIRA, Eduardo Viegas. Crime e Insegurança em Portugal - Padrões e tendências, 1985-1996. Oeiras: Celta Editora, 1998.

HECHTER, Michael. Principles of group solidarity. Berkeley, University of Califórnia Press, 1987.

LEAL, José M. P. O sentimento de (in)segurança: os casos de Mértola e da Linha de Sintra, Dissertação de Licenciatura em Sociologia e Planeamento orientada por António Firmino da Costa, ISCTE, Lisboa: Ed. Policopiada, 2001.

MCCOMBS, Maxwell. Público, quarta-feira, 6 de junho, 2001.

PORTUGAL. Código Penal Português, aprovado pelo Decreto-Lei no․ 400/82, de 23 de Setembro, alterado pelos diplomas: Decreto-Lei no. 48/95, de 15 de Março e Lei no. 65/98, de 02 de Setembro. 
PORTUGAL. Gabinete de Estudos e Planeamento do Ministério da Justiça. Inquérito de Vitimação, 1994.

ROCHÉ, Sebastian. Le sentiment d'insécurité, Paris: Presses Universitaires de France, 1993.

TÖNNIES, Ferdinand. Comunidad y Asociación. S.I.: Ediciones Península, 1979. VIEGAS, José Manuel Leite; COSTA, António Firmino da [Orgs.]. Portugal, que Modernidade? Oeiras: Celta Editora, 1998.

Recebido: 02/10/2007

Aceite final: 13/03/2008 